\title{
THE NEW NATIONAL INSTITUTE FOR MEDICAL RESEARCH
}

\section{AT MILL HILL}

BY

\author{
C. LOVATT EVANS, LL.D., D.Sc., F.R.C.P., F.R.S.
}

Emeritus Professor of Physiology in the University of London; Member of the Medical Research Council

The inauguration by His Majesty the King on May 5 of the National Institute for Medical Research at Mill Hill will be a landmark in the history of medical science in Great Britain. The Institute, representing as it does the crowning fulfilment of the recently retired secretary of the Medical Research Council, Sir Edward Mellanby, and of the first director of the precedent Institute, may be expected to continue and extend the splendid record of that Institute, which was created by the vision of the original Medical Research Committee and of its first secretary, the late Sir Walter Fletcher, and became world-famous under the leadership of its first director, Sir Henry Dale.

The building of the new Institute, designed by $\mathrm{Mr}$. Maxwell Ayrton, F.R.I.B.A., was begun in 1937, but was interrupted by the outbreak of the recent war. The completion of the structure, which was occupied by the Admiralty and used for training by the W.R.N.S. from 1942 to 1946 , the establishment of its laboratories, and the transference of equipment from Hampstead have been carried out under the supervision of the present director, Sir Charles Harington. The estimated approximate capital cost of the new buildings, excluding the scientific equipment of laboratories, was $£ 820,000$.

The premises of the former Institute at Hampstead will in future be known as "The Medical Research Council Laboratories, Hampstead," and will house various units of the Medical Research Council which cannot be placed in the new Institute. These will include the Tuberculosis Research Unit, the Human Nutrition Research Unit, the Laboratory Animals Bureau, the laboratory section of the Department for Research in Industrial Medicine (the clinical section remaining at the London Hospital), and eventually part of the Environmental Hygiene Research Unit.

\section{History of the Medical Research Council}

Since the policy of the Medical Research Council has done much to shape the course of medical research in this country, it may be well briefly to recall its history during the thirty-seven years of its life, in which it has set a fine example, perhaps the finest in the whole world, of the way in which a State can sponsor scientific research. The rapidly increasing complexity of scientific research, with its attendant high cost, has during the past few decades made it inevitable that much of the cost of the work must be put to the public expense, and it is obvious that a modern State has heavy obligations to discharge in various directions bearing on medical research. None of these obligations can be more weighty than those concerned, in the first place, with the training of medical research workers, and, in the second place, with the provision of the wherewithal for their endeavours: The first is a primary function of the university departments, though the Medical Research Council has of late years, by the provision of grants for training in research, taken its share of responsibility. The second, the main function of the Council, is discharged in a variety of ways.

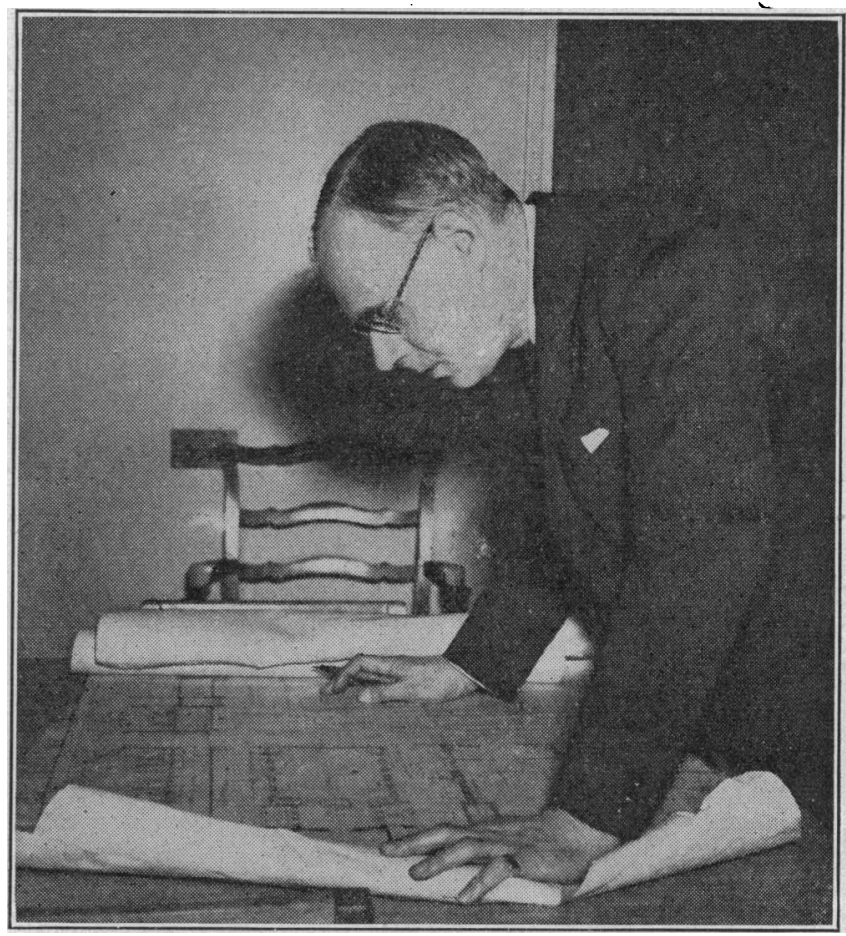

Sir Charles Harington, Director of the Institute.
An exterior view of the new building.

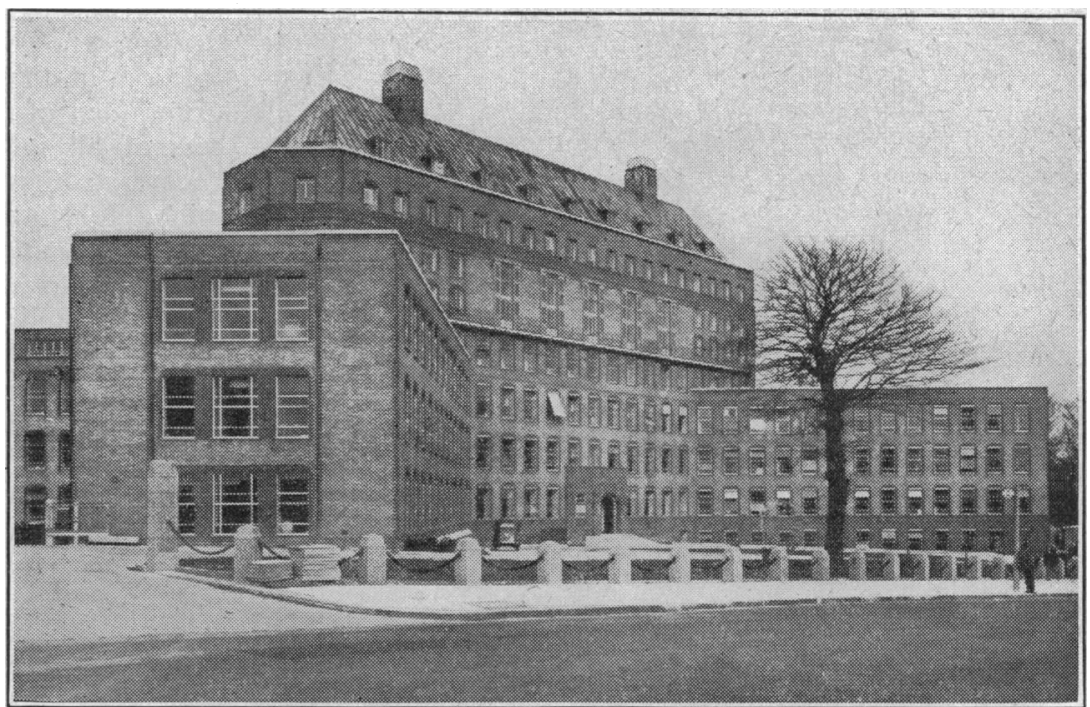




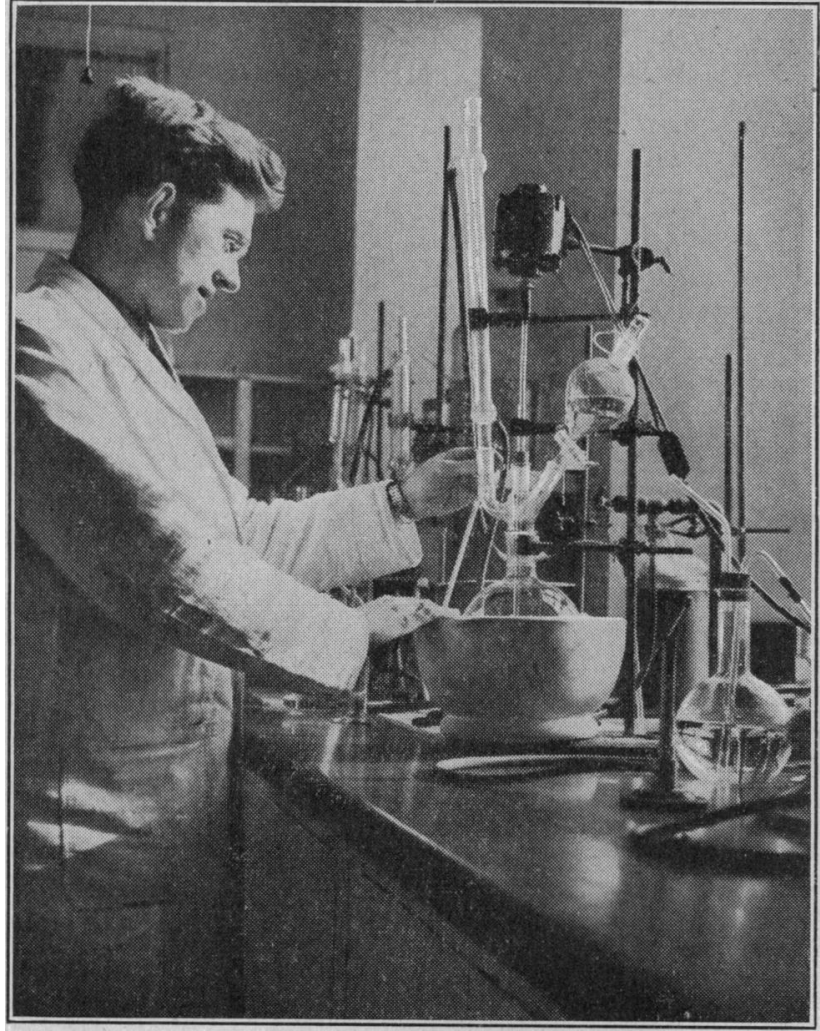

An experiment in organic chemistry.

One of the electron microscopes; this instrument gives magnification up to 60,000 diameters.

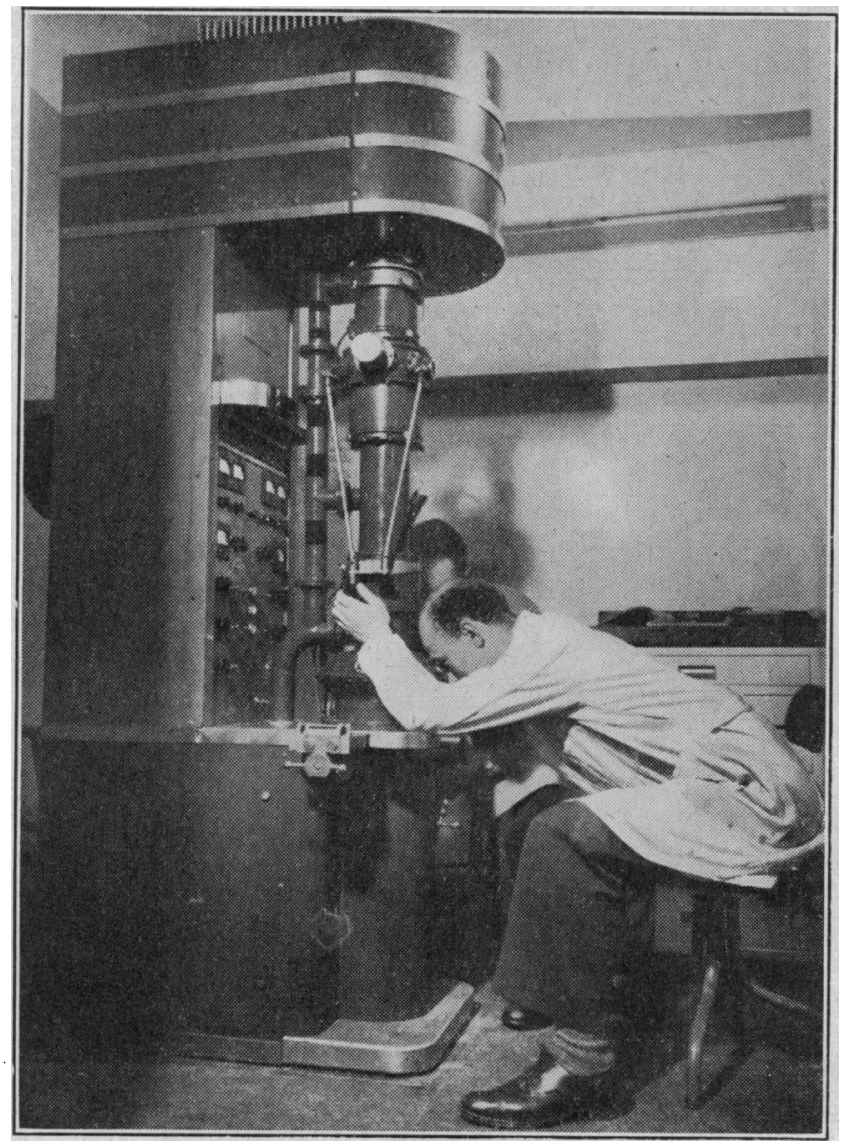

The need for such State support for medical research was already evident when the National Insurance Act of 1911 was passed. Accordingly the sum of one penny per insured person per annum was set aside for this purpose, and it was to administer the sum of $£ 55,000$,* which represented the income arising out of the first year's operation of the Act, that the original Medical Research Committee was set up. The Committee decided that medical research could be encouraged in four ways: (1) by the establishment of centralized laboratories staffed by wholetime workers ; (2) by the appointment of full- and parttime workers in university or other laboratories or in hospitals; (3) by the provision of grants to workers in academic institutions engaged in independent researches; and (4) by the establishment of a statistical department. Out of the first way grew the National Institute for Medical Research, and out of the second grew the various M.R.C. units ; the third represented, as it still does, the main item of expenditure in the budget; the fourth illustrates the Committee's awareness of the growing importance of statistical methods in all biological investigations.

The first secretary of the Committee in 1915 signed the Committee's first Report, and this made it clear that researches to be encouraged were such as had "bearing on health and disease, whether or not such researches have any direct or immediate bearing on any particular disease or class of diseases, provided that they are judged to be useful in promoting the attainment of the above object." This wise direction expressed the view of the Committee that more was often to be achieved, not only at the beginning, but also in the end, by encouraging the pursuit of knowledge in any related fields of inquiry than by the planning of ad hoc researches by the Committee as a series of frontal attacks on particular diseases. Although in some instances such frontal attacks might be indicated, and have indeed been carried out, in general the expression "the prosecution of research" correctly states the attitude of research workers, who follow up a clue wherever it may lead, the only objective being the "improvement of natural knowledge": it is in contrast to the by no means unimportant process of "development" in which natural knowledge acquired by research is brought out or exploited for a particular end, not necessarily a laudable one.

It is difficult to get laymen to believe that planning, which can sometimes be employed with such spectacular results in the latter process, is largely thrown away on the former. In striking at the outset for the academic freedom of all its workers, therefore, the Medical Research Committee of 1915 laid the very foundation for the success of all its future undertakings. Things might have been far otherwise; the Committee and all its workers might, for instance, have been drawn into the ambit of a Ministry, and have been so "cabin'd, cribb'd, confin'd, bound in to saucy doubts and fears" as to have been frustrated and to have lost that freedom from the start. Instead, when the Committee was, in 1920, reconstituted by Royal Charter as the Medical Research Council, that body was placed under the Committee of the Privy Council for Medical Research, with the Lord President of the Council as chairman.

As a consequence of this wise line of action the work of the Medical Research Council is free from political influence, and is also carried out at a surprisingly low

*The Parliamentary provision for the Medical Research Council in 1949-50, less surrenders, was $£ 1,216,000$ ordinary expenditure and $£ 319,000$ capital expenditure. 
administrative cost.* As a further consequence, it came about that by the time the Hampstead laboratories were ready for occupation by the small band of workers then employed by the Council, which was in 1920, this band took over in an atmosphere of academic freedom comparable with that prevailing in university departments.

\section{The Original Institute}

Those laboratories, which became known as the National Institute for Medical Research, had originally been built as a hospital, the Mount Vernon Hospital, Hampstead, and the property was purchased freehold in 1914 for the sum of $£ 35,000$. The outbreak of war in 1914 prevented the premises being developed as research laboratories in the manner planned by the Committee; they were taken over by the War Office and used at first, under the auspices of the Medical Research Committee, for the study of " soldier's heart" by Sir Thomas Lewis; after 1917 the hospital was used by the Canadian Forces for a time, and afterwards as a Central Hospital for Flying Officers: during that time much work on flying stress was carried out there, also under the Medical Research Committee.

The original Institute contained four "departments," one of physiology, pharmacology, and biochemistry under H. H. Dale, one of bacteriology and immunology under S. R. Douglas, one of applied physiology under Leonard Hill, and the statistical department under John Brownlee. The "library" consisted of a few books which could have been transported in a hand-barrow: it is now one of the finest of its kind in the country.

At the beginning the entire staff of the Institute was regarded as directly responsible to the Council, through its secretary. This dangerous start was put right by the appointment of $\mathbf{H}$. $H$. Dale as director of the whole Institute in 1928, with the result that much better coordination was obtained in the running of the Institute. It is this easy and flexible co-ordination which has done so much to enhance the potentialities of the whole Institute. Modern scientific work almost always demands specialization of a very high order, and because most real research deals with the unexplored fringes of knowledge it not infrequently happens that some of the most promising fields are those where two or more disciplines overlap.

It has been a common practice in the universities, as a matter of administrative expedience and as a means of procuring financial support, to create departments in such special subjects. This serves well for the production of specialists, but it has the tendency for those specialists to lose contact with other profitable lines of inquiry and, as it has often been expressed, to "know more and more about less and less." Departmentalism can be prevented only by having research workers mingle freely with one another and work in one another's laboratories: fresh interests then soon spring up, new lines of approach suggest themselves, and research teams come into being on the basis of voluntary co-operation. It is this spirit which prevails at the National Institute for Medical Research, and which grew up under the leadership of Sir Henry Dale. It is true that the research staff of the Institute is grouped into Divisions and Sections, each under the leadership of a senior investigator, but the staff are as little walled-in as are their own interests and investigations.

It had been the original intention of the Medical Research Committee to have a small research hospital in close association with its central laboratories, but by

*In 1949-50 this was only $£ 54,653$ for a total grant-in-aid (net) of $£ 1,535,000$, which excludes certain incomes, such as that from benefactions.

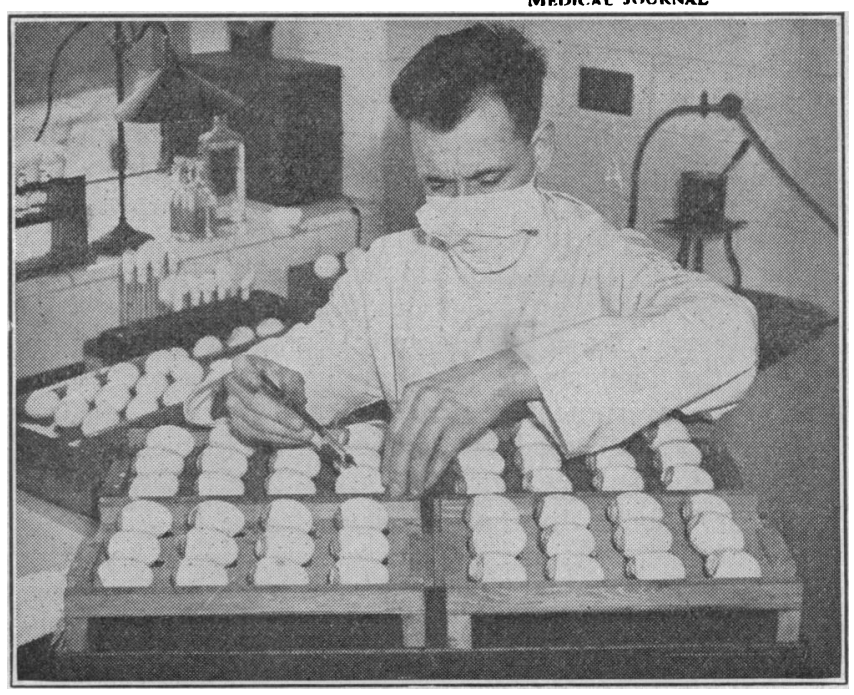

Inoculation of eggs with influenza virus.

the time the Institute at Hampstead came into use this plan was abandoned for various reasons, and contacts with clinical material were made by the establishment of separate research units, such as the one originally led by Sir Thomas Lewis at University College Hospital, or the more recently established Harvard Unit for the study of the common cold at Salisbury, the latter being a good illustration of the flexibility of the Council's outlook in virtue of which it is able, when the signs are propitious, to make facilities for a frontal attack on a particular disease. The circumstances which made it seem likely that the time might be opportune for this frontal attack on the common cold were that much laboratory-based knowledge of the viruses had accumulated in recent years ; a good amount of that knowledge-for example, the discovery of the influenza virus by Andrewes, Laidlaw, and Wilson Smith-had originated from the investigations which had been carried out at the National Institute for Medical Research, so that experts on the viruses were already working on the spot and could organize the investigation at the clinical level.

It was, in a' way, out of the requirements of virus research that the idea of the new Institute was conceived, for in 1921 the Council purchased the Mill Hill site for the original purpose of erecting thereon animal farm buildings and laboratories in which virus research work could be carried out. The first work to be undertaken there was a frontal attack on the distemper of dogs and

The Library.

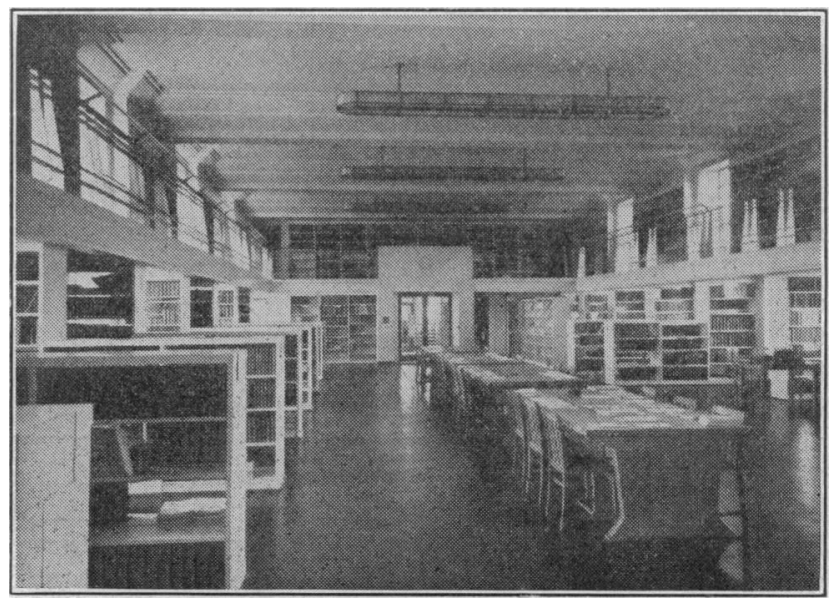


other species. This work, carried out by Laidlaw and Dunkin and financed by the Field, led to the discovery of the cause, and to a method for prevention, of dog distemper. Now another strong line of research at the National Institute was the study. of chemotherapy, and its workers had already made to this department of knowledge such important contributions as the development of the amidine drugs for the treatment of kala-azar. The Council set up a Chemotherapy Committee in 1928 to further the interests of research in this subject, and in 1936 the Government allocated an additional $£ 30,000$ per annum to the Council for financing the further development of the subject.

At the existing Institute, however, there was no possibility of further expansion, so it was decided to design for erection at the Mill Hill site an entirely new National Institute for Medical Research where better accommodation could be provided not only for the studies already in hand but also for the development of the researches in chemotherapy. A nutrition building for the study of general nutritional problems had already been erected on the site, and was in part paid for out of the Fletcher Memorial Fund. It is now some thirteen years since the building of the new Institute was begun, and, if it was true in 1937 that the Hampstead Institute was congested, by the time the new building was ready for occupation every available square foot of space at Hampstead, even to the corridors, was crammed to bursting point.

\section{The New Institute}

The new building, of noble and dignified design, has a total area of about 90,000 sq. ft. of working space, excluding the Fletcher Memorial Hall and stores. It consists of a central block with two obliquely placed wings at each end, so that all the rooms are well lighted. The central block is seven stories high, and the wings three stories above ground at the front of the building; there are basement and sub-basement floors which, owing to the slope of the ground, are at some aspects well lighted. There is accommodation for some 400 workers in all. The present staff consists of about 85 qualified research workers, about 160 technicians, and maintenance and administrative staffs. In addition to the whole-time established workers on the scientific staff, there are unestablished and temporary workers, and visitors from other parts of the country and from abroad. The estimated running cost for 1950-1, including salaries but excluding the costs of the Nutrition Building, is $£ 278,000$, as compared with $£ 204,754$ for the $1949-50$ costs of the Hampstead Institute and Farm Laboratories at Mill Hill.

The range of work which will be undertaken in the new Institute is of the most varied description, and could cover all the laboratory aspects of medical research. This can be seen from the following brief account of the laboratories.

The general arrangement is that engineering services, stores, and certain laboratories are placed on the lower ground floor; administration and fine-instrument shops on the ground floor; laboratories and animal house on the ground, first, second, and third floors; library on the fourth and mezzanine floors; canteen on the fifth floor; and club-rooms for the technical staff on the sixth floor. The laboratories are very well provided with services, which include pressure water, steam, compressed air, and direct electrical current of various voltages. Each floor has hot and cold rooms, and some of the latter are fitted for laboratory work at low temperatures. Large general stores occupy the basement of the Fletcher Memo- rial Hall, and are accessible on the one hand from a service road, and internally at a central point convenient for distribution throughout the Institute.

\section{The Divisions}

For convenience of administration the Institute is subdivided into divisions, each under the direction of a senior scientist.

Division of Chemotherapy.-This, at present the chief concern of the Institute, has the largest allocation of space. It has become clear that in the undertaking of research in this subject much effort is wasted if there is not the closest possible contact between organic chemists and biochemists on the one hand and biological workers on the other hand. Accordingly the Division is provided with associated laboratories for organic chemistry, microanalysis, hydrogenations, and large-scale chemical work, and with fully equipped biological testing laboratories. An insectarium, which cannot be housed in the main building, is being constructed in a special building outside. This Division occupies the lower ground, ground, and first floors of the south-east wing.

Division of Virus Research.-This Division is placed on the second floor of the centre block, and its work also includes that of the World Influenza Centre, which identifies the strains of influenza virus collected from epidemics in various parts of the world. Near by are large rooms for the preparation and sterilizing of media, and a section for general histological work for the general service of the Institute.

Division of Biological Standards.-This Division is one of which the Institute may justly feel very proud. As a continuation of its work in connexion with the Health Organization of the League of Nations, the Institute has a large share in the responsibility of the World Health Organization for the maintenance of International Biological Standards, and the actual International. Standard substances are stored in a cold room in this Division, which occupies part of the second floor of the north-east wing. As the work involved is very varied, much of the work of this Division is shared out among the various specialists working in other Divisions in the Institute.

Division of Experimental Biology.-This Division is an illustration of the flexibility of the organization within the Institute: it was formerly engaged almost wholly on problems of endocrinology, but, its interests having widened considerably, the title has been appropriately altered: the head of this Division is also responsible for the Experimental Animal Houses, and for the Small Animal Breeding Colony and Poultry Department housed in outlying buildings.

Division of Bacterial Chemistry.-This Division is another instance of the adaptability of the organization. Formerly an external unit under the direction of Sir Paul Fildes, it has now been assimilated as a Division working in close contact with the Divisions of Chemotherapy and Biochemistry.

Division of Physiology and Pharmacology.-This occupies the lower ground floor and basement of the north-east wing, and has developed from the laboratory (F4) at Hampstead, which, under Sir Henry Dale, contributed so much to the reputation of the Institute. The laboratory is well equipped for physiological and electrophysiological work, and works in close collaboration with the Divisions of Chemotherapy and Biochemistry.

Division of Biochemistry.-This was formerly part of the Department of Physiology and Pharmacology, and is 
now raised to the status of a Division. It occupies part of the ground and first floors of the north-east wing, and will of necessity have very close links with most of the Divisions in the Institute.

Division of Biophysics and Optics, including a Section of Physical Chemistry.-This is housed on the whole of the ground floor of the south-west wing, part of that of the north-west wing, and part of the first floor of the southeast wing. Part of the territory is fully air-conditioned. This Division is one of great value and importance to the work of the Institute as a whole, as physical techniques are finding great and increasing scope in modern biological work. One of its important activities is in connexion with the employment of isotopic elements in biological work of many different kinds. This Division has the primary responsibility for work on the radioactive isotopes used in the other laboratories, and also possesses a mass spectrometer (made in the Institute) for the estimation of stable isotopes. There are two electron microscopes, which are of the greatest value in virus research, a Tiselius electrophoresis apparatus, and much other valuable physical apparatus. The optical part of the Division has unique equipment for the employment of modern methods of microscopy, such as phase-contrast and ultra-violet microscopy.

\section{Other Sections}

Fine-instrument Shop and Electronics.-Modern laboratory work, particularly in biophysics, necessitates wellequipped fine-instrument workshops and shops for the construction of electronic apparatus, and accordingly there is an adequately equipped fine-instrument workshop attached to the Biophysics Division.

Animal House.-This essential part of the Institute occupies the first and second floors of the north-west and south-west wings, and provision is made for the accommodation of all the species in common use in the laboratories. It has forced ventilation throughout, and the cages and racks are of the most modern design, with special arrangements for sterilization, for the clean and rapid distribubution of food, and for cleaning and disposal of refuse. Dangerous infections can be dealt with in isolation units, the effluent air from which is disinfected before discharge. A very important feature is the close proximity of the animal houses to the laboratories.

Library.-This occupies the fourth and mezzanine floors of the central block, and consists of the large reading-room, ample stack-rooms, and a set of small rooms for the use of members of the staff engaged in library studies. This obviates the necessity for the provision of a rather large number of private rooms for research workers, whose time is preferably spent almost wholly in the laboratories and library and in personal contact with other workers.

Canteen and Club-rooms. - The canteen, on the fifth floor, is worked on the cafeteria system, and seats 240 . Coffee-rooms are provided for the various sections of the staff, and one of these can be divided, if required, for use as a private dining-room for the entertainment of special visitors.

Part of the space on the attic floor is used for indoor recreation for the assistant staff.

Entrance Hall, Conference Room, Fletcher Memorial Hall, and Administration.-These occupy the ground floor of the centre block. The entrance hall is divided into two parts, of which the inner one is a foyer leading to the Fletcher Memorial Hall, which commemorates the first secretary of the Council. It seats 230, and its furnishings and equipment have been provided in part from the Fletcher
Memorial Fund. It will be used for meetings of scientific societies visiting the Institute, and will be very welcome, as the Hampstead Institute had no worthy accommodation for that purpose, and meetings held there, because they always attracted a large attendance, were almost unbearably congested and uncomfortable. The Fletcher Memorial Hall has provision for cinema projection of $16-\mathrm{mm}$. and $35-\mathrm{mm}$. films, and will also be available for social functions.

The new Institute will start its life with a vitality far more abounding than any mere catalogue of laboratories could possibly suggest. It has grown up in the way that the best research institutions always do grow up-namely, as the result of fine tradition and of irresistible pressure of growth from within. The alternative method, that of building an Institute and then trying to attract workers to fill the vacuum, would be a likely road to failure. It is, after all, the people working in a place who make its reputation, and not the amount or quality of its fittings. There is no need to echo the fatuous remark that, since some of the best work has been done under uncomfortable physical conditions, better conditions for the prosecution of scientific work are a needless luxury. The surroundings and equipment of workers at the National Institute for Medical Research have always been as good as the Council could provide, and these have already yielded splendid dividends of which the nation can be proud. With the present improved, but by no means extravagant, environment, and above all with the distinguished staff with which it opens, the Medical Research Council, and its new secretary, Dr. H. P. Himsworth, can confidently anticipate for the new Institute a record of achievement as distinguished as that of its predecessor.

The illustrations are by Westwood and Johnson, Keystone Press Agency, and Central Press Photos.

\section{THIRTY YEARS AGO}

An extract from a leading article in the "British Medical Journal" of September 11, 1920, page 405:

\section{Health and the League of Nations}

"The council of the League of Nations during its meeting last month at San Sebastian gave attention to the problem of international health, and adopted the scheme drawn up by the International Health Conference held in London last April. That conference was convened by Dr. Addison, at the request of the council of the League of Nations. The constitution then drafted for an international health office under the League provided for the establishment of a general committee and of a permanent committee for executive purposes. This permanent committee would consist of members delegated by the council of the League of Nations, of the president and four members of the General Committee, of a representative of the League of Red Cross Societies, and of a representative of the International Labour Office set up under the League of Nations. The permanent committee would apply itself to drawing up new conventions or revising those that exist.

"The functions of the health organization which it is thus proposed shall be set up under the League of Nations are: (1) to advise the League on matters relating to health; (2) to co-ordinate the work of national health administration; (3) to organize rapid interchange of information on epidemic diseases and rapid action where such information affects several countries; (4) to initiate or revise international agreements for administrative action in health matters when so requested; $(5)$ to co-operate with the International Labour Office for the protection of workers against industrial diseases and injuries; (6) to co-operate with the League of Red Cross Societies in measures against world-wide epidemics; (7) to give advice on large questions of hygiene to other authorized voluntary organizations ; and (8) to organize health commissions when requested." 